\title{
The effect of personality traits on pain perception and maternal self-confidence in the postpartum period: A cross-sectional study
}

\author{
Zeliha Özşahin, Sinem Güven Santur, Bahar Koldaş, Çiğdem Karakayali Ay
}

Department of Midwifery, Faculty of Health Sciences, Inonu University, Malatya, Turkey

Received: 2021-11-08.

Accepted: 2022-01-18

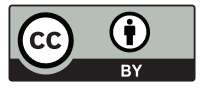

This work is licensed under a

reative Commons Attribution 4.0 International License

\section{J Clin Med Kaz 2022; 19(1):50-56}

Corresponding author:

Çiğdem Karakayali Ay.

E-mail: cigdem.karakayali@inonu.edu.tr;

ORCID: 0000-0002-5282- $973 \mathrm{X}$

\section{Abstract}

Aim: This research was conducted to determine the effect of personality traits of postpartum women on pain perception and maternal self-confidence.

Material and methods: The population of this study, which was designed as a descriptive cross-sectional study, was determined as 202 with a confidence interval of 0.95 and a power of 0.95 to represent the universe, according to the power analysis. The study was completed with 258 puerperant women. Data were collected with the "Personal Description Form", "Ten-Item Personality Scale (TIPS)", "Visual Analog Scale (VAS)" and "Pharis Self-Confidence Scale (PSCS)". In the statistical evaluation, descriptive statistics (percentage, mean, standard deviation), Pearson's correlation and multiple linear regression analysis were used.

Results: According to VAS, 25.2\% of the participants had severe pain in the legs, $27.1 \%$ in the abdomen, $46.4 \%$ in the waist, $17.4 \%$ in the chest, 30.3\% in the head, 9.4\% in the knee, $25.5 \%$ in the hips and $43 \%$ in the perineum region. The total mean score of the PSCS was $43.72 \pm 11.8$. It was found that there was a significant correlation between TIPS sub-dimensions and pain regions and total PSCS score averages $(p<0.001, p<0.05)$. As a result of multiple linear regression analysis, it was determined that the personality traits of women predicted pain and maternal self-confidence negatively and the models were statistically significant $(p<0.05)$.

Conclusions: It has been determined that personality traits have an effect on pain perception and maternal self-confidence. In line with the results obtained, midwifery interventions should be planned to reduce the perception of pain and increase maternal self-confidence.

Key words: postpartum, personality traits, pain, maternal confidence

\section{Introduction}

The postpartum period, covering the first 42 days [first 6 weeks] postpartum period, is of great importance in terms of maternal and newborn health, as it is a period in which maternal-neonatal mortality and morbidity occur most frequently as a result of physiological and psychological changes [1]. However, in the postpartum period, many women try to cope with the physiological and psychosocial changes that occur during pregnancy and childbirth [2]. In the postpartum period, women experience vaginal bleeding, cramping, bladder and intestine problems, pain in the head, perineum, back and incision site $[3,4]$. The vast majority of women perceive the experience of pain as mild or severe [5], which differs from person to person and culture to culture. It is reported that the experience of pain perception is a personal experience depending on individual psychological factors, and pain that can be easily tolerated by a person may be intolerable in another person [6]. It is stated that body perception is related to pain severity and pain duration, and women with high body perception awareness experience lower back pain in both pain severity and pain duration [7]. Appropriate evaluation and management of pain complaints occurring in the postpartum period, timely identification of complications and delivery of care are very important for health professionals and midwives [8]. During this period, pain and other complications in women can lead to inability to manage their own and their baby's 
care, causing them to have self-confidence problems $[9,10]$. In order to overcome these problems, women need strong selfconfidence and self-efficacy [8]. It was stated that self-confidence is one of the most important features required for a person to lead a happy and successful life, to fulfill the responsibilities and roles she undertakes in a healthy way, and to cope with the problems she may encounter in life more easily [8]. Studies showed that those who delivered by cesarean section experience more pain [10], and vaginal delivery is more disadvantageous on postpartum chronic pain than cesarean section [11]. However, it is stated that the baby's weight, mother's age, education level and mood during pregnancy are effective factors on the postpartum pain perception experience [12], and that physical activity has a positive effect on the postpartum pain perception experience [13]. It is stated that maternal self-confidence is affected by factors such as being educated about baby care, having experience in baby care, and feeling ready for the role of motherhood, and that mothers need information in this special period $[8,14]$. Considering that there are insufficient studies on this subject in the literature it was aimed to determine the effect of personality traits on pain perception and maternal selfconfidence in the postpartum period and to improve midwifery care in line with the results obtained. Thus, it is predicted that by determining the effect of the mother's personality traits on the postpartum period pain perception experience, the management of pain by non-pharmacological methods by midwives, and this situation may pave the way for attempts to improve maternal self-confidence.

\section{Material and methods Type of the study}

The study was conducted as cross-sectional.

\section{Population and sample of the study}

Whether the data fit the normal distribution or not was checked with the Kolmogorov Smirnov test. Since the skewness value of the model is between -2 and +2 , it has been observed that it provides a normal distribution [15]. Participants were determined by the virtual snowball chain sampling method, one of the purposive sampling methods. According to the sample calculation made using the $\mathrm{G}^{*}$ power 3.1 program, the sample size was determined as at least 202 with an effect size of 0.25 , a margin of error of 0.05 , a confidence level of 0.95 , a population representation of 0.95 , and the study was completed with 258 puerperal women.

\section{Inclusion criteria}

- Having given birth at term (38 weeks and above),

- Being in the first 7 days after birth,

- Ability to read and write,

- Having an electronic device with internet connection.

\section{Exclusion criteria}

- Filling in the form incompletely.

\section{Data collection tool}

Study data were obtained with the tools of "Personal Presentation Form", "Ten-Item Personality Scale", "Visual Analog Scale" and "Pharis Self-Confidence Scale".

\section{Personal introduction form}

The personal introduction form $[8,13,16]$ created in line with the literature reviews made by the researchers consists of a total of 17 questions including socio-demographic and obstetric characteristics.

\section{Ten-item personality scale (TIPS)}

The Ten-Item Personality Inventory, developed by Gosling et al. (2003) [17], was adapted to Turkish culture by Atak (2013) [18]. The language validity of the scale (correlations ranging between 0.92 - 0.97), exploratory (5 factors and 10 items; explained variance $65.21 \%$ ) and confirmatory (X2 /sd: 2.20, GFI (Goodness-Of-Fit İndex) .95, AGFI (Adjusted GoodnessOf-Fit İndex) .92, CFI (Comparative Fit İndex) .93, NNFI (nonnormed fit index) .91, RMR (Root Mean Square Residual) .04 and RMSEA (Root Mean Square Error Of Approximation) .03 ) factor analysis results, item analysis and criterion-resilient validity results support the suitability of the proposed five-factor model in Turkish youth. The results of reliability analysis $(n=54$; Openness to Experience 0.89, Compassion 0.87, Emotional Stability 0.89, Conscientiousness 0.87, and Extraversion 0.88) based on internal consistency (Openness to Experience 0.83, Amenability 0.81, Emotional Stability 0.83, Responsibility 0.84 and Extraversion 0.86) and test-retest method reported that the scale was acceptable and reliable [18]. It was calculated as 0.657 in this study.

\section{Visual analog scale (VAS)}

Developed by Bond and Pilowsky in 1966, the VAS is a 10 cm ruler scale defined as "no pain" at one end and "worst pain" at the other [19]. In the evaluation of VAS, $0 \mathrm{~cm}$ is defined as no pain, 1-3 cm mild pain, 4-6 moderately severe pain, and 7-10 severe pain $[20,21,3]$. This scale was adapted to Turkish by Aslan and Öztürk [22].

\section{Pharis self-confidence scale (PSCS)}

The scale was first developed by Pharis (1978). It was adapted into Turkish by Çalışır [23]. The Pharis Self-Confidence Scale, which is a 13-item five-point measurement tool, measures a parent's feelings of self-confidence about daily baby care. Each infant care item is rated from 1 to 5 (not at all, very little, moderately, very much, completely). The increase in the total score obtained from the scale indicates that the self-confidence levels of the mothers increase in baby care. The lowest score on the "Pharis Self-Confidence" scale is 13, the highest score is 65. In his study, Cronbach's alpha reliability coefficient was found to be 0.85 . In this study, it was calculated as 0.95 .

\section{Data collection}

The data were collected by the researchers via google form. Postpartum women were contacted separately via the mobile network system and the informed consent form was approved before the scale questions using the google forms method. Again, using the google forms method, data collection forms were sent to the participants via WhatsApp and the answers were digitally archived. It took approximately 10 minutes to fill out this form.

\section{Ethical aspect of research}

Approval was obtained from the Inonu University Health Sciences Non-Interventional Clinical Research Ethics Committee (Decision No:2021/2264) to conduct the study. Participants were informed about the study and postpartum women who volunteered were included in the study.

\section{Evaluation of data}

The data were evaluated by creating a data set in the IBM SPSS Statistics for Windows, Version 25.0 package program on the computer, descriptive statistical analyzes (frequency distribution, mean, standard deviation), correlation and linear regression analysis were used. Statistical significance was accepted as $\mathrm{p}<0.05, \mathrm{p}<0.01$. 


\section{Results}

It was determined that the mean age of the puerperant women participating in the study was $28.75 \pm 5.57,39.1 \%$ of them were high school graduates, $70.2 \%$ of them were not working and $82.9 \%$ of them had a planned pregnancy. It was determined that $46.1 \%$ of the participants had problems during pregnancy, $85.3 \%$ received social support, $25.8 \%$ went to nine or more controls, and $55.4 \%$ performed these controls in a state hospital (Table 1).

\begin{tabular}{|c|c|c|}
\hline \multirow{3}{*}{\begin{tabular}{l}
\multicolumn{1}{c}{ Table 1} \\
Variables \\
Education Level
\end{tabular}} & \multirow{3}{*}{$\mathbf{n}$} & \multirow{2}{*}{$\begin{array}{l}\text { ic } \\
\text { 58) } \\
\%\end{array}$} \\
\hline & & \\
\hline & & Education Level \\
\hline Primary School & 44 & 17.1 \\
\hline Middle School & 51 & 19.8 \\
\hline High School & 101 & 39.1 \\
\hline University and Above & 62 & 24.0 \\
\hline \multicolumn{3}{|l|}{ Working Status } \\
\hline Working & 77 & 29.8 \\
\hline Not Working & 181 & 70.2 \\
\hline \multicolumn{3}{|l|}{ Income State } \\
\hline Low & 21 & 8.1 \\
\hline Middle & 205 & 79.5 \\
\hline High & 32 & 12.4 \\
\hline \multicolumn{3}{|l|}{ Living Place } \\
\hline City Center & 131 & 50.8 \\
\hline District & 82 & 31.8 \\
\hline Village & 45 & 17.4 \\
\hline \multicolumn{3}{|l|}{ Planned Pregnancy } \\
\hline Yes & 214 & 82.9 \\
\hline No & 44 & 17.1 \\
\hline \multicolumn{3}{|c|}{ Having Problems During Pregnancy } \\
\hline Yes & 119 & 46.1 \\
\hline No & 139 & 53.9 \\
\hline \multicolumn{3}{|l|}{ Type Of Problem Experienced } \\
\hline Pyhsically & 83 & 32.2 \\
\hline Psychosocial & 25 & 9.7 \\
\hline Other & 150 & 58.1 \\
\hline \multicolumn{3}{|c|}{ Getting Support During Pregnancy } \\
\hline Yes & 220 & 85.3 \\
\hline No & 38 & 14.7 \\
\hline \multicolumn{3}{|c|}{ Control Frequency During Pregnancy } \\
\hline 1-2 times & 18 & 7 \\
\hline 3-4 times & 45 & 17.4 \\
\hline 5-6 times & 67 & 26 \\
\hline 7-8 times & 62 & 24 \\
\hline 9 and above & 66 & 25.6 \\
\hline \multicolumn{3}{|c|}{ Preferred Organization For Control } \\
\hline Family Health Center & 36 & 14 \\
\hline Public Hospital & 143 & 55.4 \\
\hline University Hospital & 21 & 8.1 \\
\hline Private Hospital & 58 & 22.5 \\
\hline \multirow[t]{2}{*}{ Total } & 258 & 100 \\
\hline & \multicolumn{2}{|c|}{ Mean \pm SD } \\
\hline Age (years) & \multicolumn{2}{|c|}{$28.75 \pm 5.57$} \\
\hline Size $(\mathrm{cm})$ & \multicolumn{2}{|c|}{$163.7 \pm 11.0$} \\
\hline Weight (kg) & \multicolumn{2}{|c|}{$71.28 \pm 11.3$} \\
\hline Marriage Duration & \multicolumn{2}{|c|}{$6.58 \pm 5.21$} \\
\hline Number Of Pregnancies & \multicolumn{2}{|c|}{$2.28 \pm 1.1$} \\
\hline Number Of Living Children & \multicolumn{2}{|c|}{$1.9 \pm 1.02$} \\
\hline
\end{tabular}

TIPS sub-dimensions and total PSCS mean scores were given in Table 2. The extroversion sub-dimension mean score of the postpartum women was $7.89 \pm 2.02$, the emotional stability sub-dimension mean score was $7.74 \pm 1.91$, the openness to experiences sub-dimension mean score was $6.94 \pm 2.16$, and the conscientiousness sub-dimension mean score was $7.86 \pm 1.95$, the mean score of the sub-dimension of agreeableness was $8.20 \pm 1.59$, and the total mean score of PSCS was $43.72 \pm 11.8$ (Table 2).

\begin{tabular}{ll} 
Table 2 & $\begin{array}{l}\text { TIPI Sub-Dimensions and PSCS Total Score } \\
\text { Averages }(\mathrm{n}=258)\end{array}$ \\
\hline Variable & Mean \pm SD \\
\hline Extraversion & $7.89 \pm 2.02$ \\
Emotional Stability & $7.74 \pm 1.91$ \\
Openness To Experiences & $6.94 \pm 2.16$ \\
Conscientiousness & $7.86 \pm 1.95$ \\
Agreeableness & $8.20 \pm 1.59$ \\
Total Score Average & $43.72 \pm 11.8$ \\
\hline
\end{tabular}

SD= Standard Deviation, TIPI; Ten-İtem Personality İnventory, PSCS; Pharis Self-confidence Scale

The distribution of visual analog scale scores according to the regions where postpartum women experience pain was given in Table 3 . In the study, $25.2 \%$ of the participants stated that they experienced severe pain in the leg region, $27.1 \%$ in the abdomen, $46.4 \%$ in the lumbar region, $17.4 \%$ in the chest region $30.3 \%$ in the head region, $9.4 \%$ in the knee region, $25.5 \%$ in the hip region and $43 \%$ in the perineum region (Table 3 ).

\section{Table 3}

Distribution of Participants' Visual Analogue Scale Scores by Regions Where They Experience Pain $(n=258)$

\begin{tabular}{|c|c|c|c|c|c|}
\hline \multirow{2}{*}{$\begin{array}{l}\text { Variables } \\
\text { Extraversion }\end{array}$} & \multicolumn{5}{|c|}{ VAS Pain Scores (n \%) } \\
\hline & $\begin{array}{l}\text { No Pain } \\
\text { (0) }\end{array}$ & $\begin{array}{l}\text { Mild } \\
\text { Severe } \\
\text { Pain (1-3) }\end{array}$ & $\begin{array}{l}\text { Moderate } \\
\text { Pain (4-6) }\end{array}$ & $\begin{array}{l}\text { Severe } \\
\text { Pain (7- } \\
\text { 10) }\end{array}$ & Total \\
\hline Leg & $70(27.1)$ & $79(30.6)$ & $44(17.1)$ & 65 (25.2) & $258(100)$ \\
\hline Abdominal & 40 (15.5) & $106(41.1)$ & $42(16.3)$ & $70(27.1)$ & \\
\hline Waist & 43 (16.7) & $66(25.6)$ & 29 (11.3) & $120(46.4)$ & \\
\hline Chest & 100 (38.8) & 69 (26.7) & 44 (17.1) & 45 (17.4) & \\
\hline Head & $88(34.1)$ & $65(25.2)$ & $27(10.4)$ & $78(30.3)$ & \\
\hline Knee & $116(45)$ & $91(35.2)$ & 27 (10.4) & $24(9.4)$ & \\
\hline Hip & 83 (32.2) & $66(25.6)$ & 43 (16.7) & $66(25.5)$ & \\
\hline Perineum & 47 (18.2) & $66(25.6)$ & $34(13.2)$ & $111(43)$ & \\
\hline
\end{tabular}

VAS: Visuel Analog Skala, n; numbers; \%; percent.

The relationship between TIPS sub-dimensions, pain regions, and total PSCS score averages were given in Table 4. A statistically significant negative correlation was found between the extraversion sub-dimension and leg pain, headache, knee pain, hip and perineal pain. A statistically significant correlation was found between the emotional stability sub-dimension and all pain regions, and a statistically significant relationship was found between the PSCS total score and positively. A statistically significant negative correlation was found between the sub-dimension of openness to experiences and headache and perineal pain, between the responsibility sub-dimension and leg, low back pain, chest pain, headache, hip and perineal pain, and between the mildness sub-dimension and head, hip and perineal pain (Table 4). 


\begin{tabular}{|c|c|c|c|c|c|c|c|c|c|c|c|c|}
\hline \multirow[t]{2}{*}{ Variable } & \multicolumn{2}{|c|}{ Extraversion } & \multicolumn{2}{|c|}{ Emotional Stability } & \multicolumn{2}{|c|}{$\begin{array}{l}\text { Openness to } \\
\text { Experiences }\end{array}$} & \multicolumn{2}{|c|}{ Conscientiousness } & \multicolumn{2}{|c|}{ Agreeableness } & \multicolumn{2}{|c|}{ PCSC total } \\
\hline & $\mathbf{r}$ & $\mathbf{p}$ & $\mathbf{r}$ & p & $\mathbf{r}$ & p & $\mathbf{r}$ & p & $\mathbf{r}$ & p & $\mathbf{r}$ & p \\
\hline Leg area & -.131 & .036 & -.140 & .024 & .035 & .581 & -.189 & .002 & -.113 & .071 & -.365 & .000 \\
\hline $\begin{array}{l}\text { Abdominal } \\
\text { Area }\end{array}$ & -.076 & .223 & -.132 & .034 & -.040 & .523 & -.119 & .056 & -.048 & .440 & -.273 & .000 \\
\hline Waist Area & -.063 & .316 & -.187 & .003 & .065 & .297 & -.184 & .003 & -.020 & .745 & -.327 & .000 \\
\hline Chest Area & -.058 & .350 & -.186 & .003 & -.033 & .593 & -.182 & .003 & -.103 & .099 & -.322 & .000 \\
\hline Head Area & -.156 & .012 & -.324 & .000 & -.161 & .010 & -.313 & .000 & -.205 & .001 & -.451 & .000 \\
\hline Knee Area & -.147 & .018 & -.135 & .030 & -.003 & .964 & -.091 & .147 & -.095 & .130 & -.307 & .000 \\
\hline Hip Area & -.162 & .009 & -.215 & .000 & -.010 & .869 & -.155 & .013 & -.160 & .010 & -.330 & .000 \\
\hline $\begin{array}{l}\text { Perineum } \\
\text { Area }\end{array}$ & -.231 & .000 & -.337 & .000 & -.126 & .043 & -.290 & .000 & -.265 & .000 & -.304 & .000 \\
\hline
\end{tabular}

TIPI; Ten-İtem Personality İnventory, PSCS; Pharis Self-confidence Scale, r; Pearson correlation analysis, The correlation is significant at the $\mathrm{p}<0.01$ level. The correlation is significant at the $\mathrm{p}<0.05$ level.

Table 5

TIPI Multiple Linear Regression Analysis Results on the Predictions of Pain and PSCS by Sub-Dimensions

\begin{tabular}{|c|c|c|c|c|c|c|c|c|c|}
\hline $\begin{array}{l}\text { Variables } \\
\text { Extraversion }\end{array}$ & Leg & Abdominal & Waist & Chest & Head & Knee & Hip & Perineum & PSCS Total \\
\hline B & -.131 & -.076 & -.063 & -.058 & -.156 & -.147 & -.162 & -.231 & .627 \\
\hline $\mathbf{t}$ & -2.108 & -1.220 & -1.004 & -.936 & -2.520 & -2.376 & -2.629 & -3.802 & 12.890 \\
\hline$\beta$ & -.065 & -.038 & -.031 & -.029 & -.077 & -.073 & -.081 & -.115 & Oca.99 \\
\hline R2 & .017 & .006 & .004 & .003 & .024 & .022 & .026 & .053 & .394 \\
\hline $\mathbf{F}$ & 4.443 & 1.490 & 1.009 & .876 & 6.353 & 5.645 & 6.911 & 14.456 & 166.55 \\
\hline $\mathbf{p}$ & .036 & .223 & .316 & .350 & .002 & .018 & .009 & .000 & .000 \\
\hline \multicolumn{10}{|c|}{ Emotional Stability } \\
\hline B & -.140 & -.132 & -.063 & -.186 & -.031 & .135 & -.215 & -.337 & .651 \\
\hline $\mathbf{t}$ & -2.264 & -2.134 & -3.046 & -3.030 & -5.481 & -2.187 & -3.529 & -5.724 & 13.713 \\
\hline$\beta$ & -.075 & -.070 & -.099 & -.099 & -.172 & -.072 & -.115 & -.179 & 2.214 \\
\hline $\mathbf{R} 2$ & .020 & .017 & .035 & .035 & .105 & .018 & .046 & .113 & .423 \\
\hline $\mathbf{F}$ & 5.149 & 4.555 & 9.277 & 9.179 & 30.037 & 4.785 & 12.453 & 32.761 & 188.043 \\
\hline p & .024 & .034 & .003 & .003 & .000 & .030 & .000 & .000 & .000 \\
\hline \multicolumn{10}{|c|}{ Openness To Experiences } \\
\hline B & .029 & .040 & .065 & -.033 & -.161 & -.003 & -.029 & -.126 & .582 \\
\hline $\mathbf{t}$ & .553 & -.640 & 1.046 & -.535 & -2.606 & -.045 & -.165 & -2.029 & 11.464 \\
\hline$\beta$ & -.016 & -.018 & .030 & -.015 & -.074 & -.001 & .005 & -.058 & 2.106 \\
\hline $\mathbf{R 2}$ & .001 & .002 & .004 & .001 & .026 & .000 & .000 & .016 & .339 \\
\hline $\mathbf{F}$ & .306 & .410 & 1.094 & .286 & 6.791 & .002 & .027 & .027 & 131.417 \\
\hline p & .591 & .523 & .297 & .593 & .010 & .964 & .869 & .869 & .000 \\
\hline \multicolumn{10}{|c|}{ Conscientiousness } \\
\hline B & -.189 & -.119 & -.184 & -.182 & -.313 & -.091 & -.155 & -.290 & .701 \\
\hline $\mathbf{t}$ & -3.086 & -1.918 & -2.995 & -2.958 & -5.279 & -1.455 & -2.505 & -4.841 & 15.713 \\
\hline$\beta$ & -.091 & -.057 & -.088 & -.087 & -.150 & -.043 & -.074 & -.139 & 2.151 \\
\hline R2 & .036 & .014 & .034 & .033 & .098 & .008 & .024 & .084 & .491 \\
\hline $\mathbf{F}$ & .9 .523 & 3.677 & 8.970 & 8.749 & 27.868 & 2.116 & 6.276 & 24.433 & 246.902 \\
\hline p & .002 & .056 & .003 & .003 & .000 & .147 & .013 & .000 & .000 \\
\hline \multicolumn{10}{|c|}{ Agreeableness } \\
\hline B & .035 & -.048 & -.020 & -.103 & -.205 & .035 & -.160 & -.265 & .582 \\
\hline$t$ & -1.814 & -.774 & -.326 & -1.657 & -3.344 & -1.519 & -2.599 & -4.406 & 11.464 \\
\hline$\beta$ & -.064 & -.027 & -.012 & .058 & -.116 & -.053 & -.091 & -.150 & 2.106 \\
\hline $\mathbf{R 2}$ & .013 & .002 & .000 & .011 & .042 & .009 & .026 & .070 & .339 \\
\hline $\mathbf{F}$ & 3.292 & .599 & .106 & 2.747 & 11.181 & 2.308 & 6.754 & 19.410 & 131.417 \\
\hline $\mathbf{p}$ & .071 & .440 & .745 & .099 & .001 & .130 & .010 & .000 & .000 \\
\hline
\end{tabular}

TIPI; Ten-İtem Personality İnventory, PSCS; Pharis Self-confidence Scale, B; unstandardized coefficient of regression, $\beta$, standardized coefficient of regression, $\mathrm{R}^{2}$ : coefficient of determination, , $\mathrm{p} 1<0.05$; F test result for the significance of the model, $\mathrm{p} 2<0.05$; $t$ test result for the significance of the regression coefficients 
As a result of the analyzes, it was determined that personality traits in the postpartum period predicted pain and maternal self-confidence in a negative way and the established models were statistically significant. When the $\mathrm{R}^{2}$ values of the models were examined, $1 \%$ of the pain in the leg area, $2 \%$ of the headache, $2 \%$ of the pain in the hip area, $5 \%$ of the pain in the perineum and $39 \%$ of the maternal self-confidence were explained by the extraversion sub-dimension of the ten-item personality traits scale.

In the study, $2 \%$ of the pain in the leg area, $1.7 \%$ of the pain in the abdomen, $3.5 \%$ of the pain in the chest area, $10.5 \%$ of the headache, $1.8 \%$ of the pain in the knee area, $4.6 \%$ of the pain in the hip area, $11.3 \%$ of pain in the perineum and $42.3 \%$ of maternal self-confidence were explained by the emotional stability sub-dimension of the ten-item personality traits scale.

$2.6 \%$ of headache and $33.9 \%$ of maternal self-confidence were explained by the openness to experiences sub-dimension of the ten-item personality traits scale.

According to the results, $3.6 \%$ of pain in the leg region, $3.4 \%$ of pain in the lumbar region, $3.3 \%$ of headache, $2.4 \%$ of pain in the hip region, $8.4 \%$ of pain in the perineum and $49.1 \%$ of maternal self-confidence were explained by the responsibility sub-dimension of the ten-item personality traits scale.

$4.2 \%$ of headache, $2.6 \%$ of hip pain, $7 \%$ of perineal pain and $33.9 \%$ of maternal self-confidence were explained by the ten-item personality traits scale's agreeableness sub-dimension.

Starting from the equations that can be established regarding the regression models, a 1-unit increase in the extraversion sub-dimension score causes a decrease of -.065 in the leg area, -.077 in the head region, -.073 in the knee region, -.081 in the hip region, -.115 in the perineum region, and an increase of 1.99 units in maternal self-confidence. A 1-unit increase in the emotional stability sub-dimension score causes an increase of -.075 in the leg region, -.070 in the abdomen, -.099 in the waist region, -.099 in the chest region, -.172 in the head region, -.072 in the knee region, -.115 in the hip region, -.179 in the perineum region, and 2,214 units on maternal self-confidence. A 1-unit increase in the openness to experiences sub-dimension score causes a -.074-unit decrease in the head area and an increase of 2.106-unit on maternal self-confidence. A 1-unit increase causes a decrease of in the Responsibility sub-dimension score -.091 in the leg region, -.088 in the waist region, -.087 in the chest region, -.150 in the head region, -.074 in the hip region, -.139 in the perineum region, and an increase of 2.151 in the maternal selfconfidence. A 1-unit increase in the Compassion sub-dimension score causes a -.116-unit decrease in the head region, -.091-unit decrease in the hip region, -.150-unit decrease in the perineum region, and an increase of 2.106-unit in maternal self-confidence (Table 5). Consequently, it can be said that the personality traits of extraversion, emotional stability, openness to experiences, responsibility and agreeableness accompany low levels of pain and high maternal self-confidence in the postpartum period.

\section{Discussion}

After pregnancy, which is the most special stage of a woman's life, in the postpartum period, the mother transitions to a new process socially and psychologically. In this process, being able to carry out and manage social and psychological processes in a healthy way is closely related to the personality traits of the mother [24]. Considering the studies on personality traits in the postpartum period, studies on postpartum depression and breastfeeding [25-28] were found.

In this study, personality traits sub-dimensions mean scores were found to be extroversion $7.89 \pm 2.02$, emotional stability $7.74 \pm 1.91$, openness to experience $6.94 \pm 2.16$, conscientiousness $7.86 \pm 1.95$, and agreeableness $8.20 \pm 1.59$. In Brown's study, personality traits sub-dimensions score averages were determined as $8.41 \pm 2.42$ for extraversion, $7.50 \pm 2.63$ for emotional stability, $6.94 \pm 2.57$ for openness to experience, $8.75 \pm 2.47$ for conscientiousness, and $8.47 \pm 2.47$ for agreeableness [26]. In the study conducted by Sunay et al., the mean scores of personality traits sub-dimensions were found to be $8.92 \pm 3.33$ for extraversion, $8.90 \pm 3.09$ for emotional stability, $9.00 \pm 3.25$ for openness to experience, $10.51 \pm 3.16$ for conscientiousness, and $11.14 \pm 3.16$ for agreeableness [25]. In this study, it was seen that the average score of personality traits sub-dimensions was slightly lower than the literature. The reason for this may be that the data was obtained online. More realistic results may have been obtained since postpartum women answered questions more comfortably in online interviews than in face-to-face interviews.

Pain is a condition that can cause negative consequences in many areas of life, both physically and psychologically. It is known that pain affects people's quality of life. The negative effect of pain on dynamic physiological and psychological processes in the postpartum period is inevitable [29]. Therefore, examining pain, considering the role of women in mental and physical health, is necessary for improved health and treatment process [5]. In this study, it was found that pain was felt in the leg, abdomen, waist, chest, knee, hip and perineum region in the postpartum period, and that the majority of puerperal women experienced severe pain in the low back, perineum and head region. It was stated that $25-68 \%$ of women experience low back pain in the postpartum period [13]. In this study, it was determined that $46.4 \%$ of puerperant women had severe low back pain and $29 \%$ had moderate low back pain. People who experience similar levels of pain intensity may react differently. The most important factors affecting the perception of pain and enduring pain are individual characteristics, including psychological and personality traits [5]. In this study, it was determined that postpartum women with extrovert personality traits experienced less leg, head, knee, hip and perineal pain, that puerperant women, who had more emotionally balanced personality traits, experienced less leg, abdomen, waist, chest, knee, hip and perineal pain, that puerperant women who had personality traits that were open to experiences experienced less headache and perineal pain, that puerperant women with higher level of responsible personality traits experienced less leg, waist, chest, head, hip and perineal pain, and puerperal women with mildness personality traits experienced less head, hip and perineal pain. In a study, it was determined that there is a strong relationship between personality traits and headaches $[30,31]$. In the study of Yadolahi et al., a relationship was found between personality traits and pain [5]. In the studies conducted by Özsoy et al. (2018) and Jalali and Ghaleban (2005), no significant relationship was found between personality traits and pain perception $[6,32]$. According to the results of the literature, our research finding was similar to the studies that found a relationship between personality traits and pain, but differs from the studies that did not.

Looking at the relationship between maternal selfconfidence and areas of pain, a statistically significant negative correlation was found between self-confidence and pain perception. It was observed that as maternal self-confidence increased, perceived pain decreased in each region. Selfconfidence is the psychological prerequisite for meaningful, happy, satisfying, loving and balanced moments [33]. In this context, every effort of midwives to increase self-confidence will contribute to the realization of this prerequisite and contribute to less perception of pain. 
Self-confidence is defined as a dynamic cognitive process that explains a personal belief to successfully perform a necessary behavior in a given situation. Self-confidence is an important prerequisite for behavior change and self-control $[33,34]$. It has a vital role for the mother and baby in the postpartum period [26]. Women's low self-confidence creates a negative self-perception that increases guilt, shame, feelings of worthlessness, helplessness, and ultimately frustration, depression, and motivational impairment of problem-solving ability [35]. High maternal self-confidence is needed for the positive development of children [36]. In studies conducted in the postpartum period in Turkey, the mean PSCS score was $50.2 \pm 9.5$ [9]. It was determined as $42.6 \pm 6.2$ [2]. In this study, the mean total score of maternal self-confidence was determined as $43.72 \pm 11.88$. Considering the maximum score that can be obtained from the scale 65 , we can say that there was a medium level of maternal self-confidence. For this reason, midwives should aim to develop self-confidence by constantly supporting mothers in the postpartum period.

Moreover, a 1-unit change in the extraversion subdimension score causes a decrease of .077 in the perception of headache, .081 in the hip region, .115-unit in the perineum, and an increase of 1.99 units in the total maternal self-confidence score. A 1-unit change in emotional stability sub-dimension score causes an increase of -.075 units in the leg region, -.070, in the abdomen region, -.099 in the waist region, -.099 in the chest region, -.172 in the head region, -.072 in the knee region, -.115 in the hip region, -.179 in the perineum, and an increase of 2.214 in maternal self-confidence. A 1-unit increase in the openness to experiences sub-dimension score causes a -.074unit decrease in the head area and an increase of 2.106-unit on maternal self-confidence. A 1-unit increase in the Responsibility sub-dimension score causes a decrease of -.091 in the leg region, -.088 in the waist region, -.087 in the chest region, -.150 in the head region, -.074 in the hip region, -.139 in the perineum region, and an increase of 2.151 in the maternal self-confidence. A1unit increase in the agreeableness sub-dimension score causes a decrease of -.116 in the head area, -.091 in the hip region, -.150 in the perineum, and an increase of 2.106 units in maternal selfconfidence. These findings showed that personality traits were an effective variable in reducing pain perception and increasing maternal self-confidence in postpartum women. Since there is no study supporting this finding, it is thought that our study result will contribute to the literature.

\section{Conclusion}

As a result, it was determined that personality traits have a significant effect on pain perception and maternal self-confidence in the postpartum period. In the postpartum period, it is important to eliminate the perception of pain with pharmacological or nonpharmacological methods in accordance with the personality characteristics and preferences of women and to establish selfconfidence communication with mothers. In this context, we think that maternal self-confidence can increase as puerperant women are informed about pain, baby care, psychological processes and parental identity by midwives and nurses during the early postpartum period that they stay in the hospital.

\section{Limitation of the study}

The limitation of this study is that puerperant women who did not have internet on their phones and did not know how to use mobile devices could not be included in the study because google forms were used in the study. Our findings cannot be generalized to all pregnant women since the research was carried out on google forms, and a certain population could be reached, and more studies are needed in this area.

Disclosures: There is no conflict of interest for all authors.

Acknowledgements: We thank the postpartum women who participated in the study.

Funding: The financial support for this study was provided by the investigators themselves.

\section{References}

1. World Health Organization (WHO). "WHO Recommendations On Postnatal Care Of The Mother And Newborn” 2013. Erişim: 11.10.2021.

2. Aydemir S, Onan N. The relationship between maternal self confdence and postpartum depression in primipara mothers: a follow up study. Community Ment Health J. 2020; 56(8): 1449-56. https://doi.org/10.1007/s10597-020-00588-6

3. Chang S, Chen K, Lee C, Shyu M, Lin M, Lin W. Relationships between perineal pain and postpartum depressive symptoms: A prospective cohort study. Int J Nurs Stud. 2016; 59: 68-78. https://doi.org/10.1016/j.ijnurstu.2016.02.012

4. ACOG. Postpartum Pain Management. https://www.acog.org/womens health/faqs/postpartum-pain-management. 2020. Accesed 18.10.2021

5. Yadollahi P, Khalaginia Z, Vedadhir A, Ariashekouh A, Taghizadeh Z, Khormaei F. The study of predicting role of personality traits in the perception of labor pain. Iran J Nurs Midwifery Res. 2014;19(7 Suppl 1):S97-S102.

6. Özsoy F, Yıldız M, Gülücü S, Kulu M. Relationship between birth pain and some psychiatric features. KSU Med Fac J. 2018; 13(2):437. https://doi.org/10.17517/ksutfd.427762

7. Goossens N, Geraerts I, Vandenplas L, Veldhoven VA, Asnong A, Janssens L. Body perception disturbances in women with pregnancyrelated lumbopelvic pain and their role in the persistence of pain postpartum". BMC Pregnancy Childbirth. 2021; 21(1):219. https:// doi.org/10.1186/s12884-021-03704-w

8. Öztürk S, Erci B. The effect of traınıng provided the prımıparas in the postpartum perıod for motherhood and neonatal care on maternal self-confidence. GUSBD. 2016; 5(2):25-31.

9. Evcili F, Bekar M, Yurtsal B, Abak G, Tali B, Temel S. The evaluation of readiness for maternal role and self-confidence among women in postpartum period. STED. 2018; 27: 56-61.

10. Pereira T, Souza FG, Beleza A. Implications of pain in functional activities in immediate postpartum period according to the mode of delivery and parity: an observational study. Braz J Phys Ther. 2017; 21(1):37-43. https://doi.org/10.1016/j.bjpt.2016.12.003

11. Lavand'homme P. Postpartum chronic pain. Minerva Anestesiol. 2019; 85(3):320-24. https://doi.org/10.23736/S0375-9393.18.13060-4 
12. Di Filippo A, Bitossi U, Marcellino V, Limatola V, Sicurani M, Borracci, T, et al. Use of the CompuFlo ${ }^{\circledR}$ system to identify the epidural space in obstetric-gynecological area. A single-center retrospective study. Minerva Anestesiol. 2020; 86(1):99-100. https://doi. org/10.23736/S0375-9393.19.13857-6

13. Girard MP, O'Shaughnessy J, Doucet C, Ruchat SM, Descarreaux M. Association between physical activity, weight loss, anxiety, and lumbopelvic pain in postpartum women. J Manipulative Physiol Ther. 2020; 43(6):655-66. https://doi.org/10.1016/j.jmpt.2019.11.008

14. Şayık D, Örsal Ö. The self-efficacy of parents of newborns in Turkey and the factors that influence their self-efficacy: A Systematic Review. Osmangazi of Med J. 2019; 41(4):434-47. https://doi.org/10.20515/otd.475583

15. Alpar C. Spor Sağlık ve Eğitim Bilimlerinden Örneklerle Uygulamalı İstatistik ve Geçerlik Güvenirlik. In Detay Yayıncılık; 2018. p. 672.

16. Erdemoğlu Ç, Özşahin Z, Altıparmak S. The effect of personality traits of pregnants and their ways of coping with stress on the fear of childbirth. Jour Turk Fam Phy. 2019; 10(3):130-39. https://doi.org/10.15511/tjtfp.19.00330

17. Gosling SD, Rentfrow PJ, Swann Jr WB. A very brief measure of the Big-Five personality domains. J. Res. Pers. 2003; 37:504-528. https://doi.org/10.1016/S0092-6566(03)00046-1

18. Atak H. The Turkish Adaptation of the Ten-Item Personality Inventory”. Noro Psikiyatr Ars. 2013; 50:312-19. https://doi.org/10.4274/ npa.y6128

19. Bond MR, Pilowsky I. Subjective assessment of pain and its relationship to the administration of analgesics in patients with advanced cancer. J Psychosom Res. 1996; 10(2):203-8. https://doi.org/10.1016/0022-3999(66)90064-x

20. Sriwatanakul K, Kelvie W, Lasagna L, Calimlim FJ, Weis OF, Mehta G. Studies with different types of visual analog scales for measurement of pain. Clin Pharmacol Ther.1983; 34(2):234-9. https://doi.org/10.1038/clpt.1983.159

21. Hawker GA. Mian S. Kendzerska T. French M. Measures of adult pain: visual analog scale for pain (VAS pain). numeric rating scale for pain (NRS pain). McGill pain questionnaire (MPQ). short-form McGill pain questionnaire (SF-MPQ). chronic pain grade scale (CPGS). short form-36 bodily pain scale (SF-36 BPS). and measure of intermittent and constant osteoarthritis pain (ICOAP). Arthritis Care Res. 2011; 63(S11):240-52. https://doi.org/10.1002/acr.20543

22. Aslan FE. Öztürk KZ. Pain measurement and assessment.In: Eti FA, editor. Pain Nature and Control. 1 nd ed. Ankara: Academician Bookstore; 2014. p.67-100.

23. Çalışı H. Examination of the factors affecting the motherhood role performance of first-time mothers. Ege University. Health Sciences Institute. Unpublished Doctoral Thesis. Izmir. 2003.

24. Josefsson A, Larsson C, Sydsjö G, Nylander PO. Temperament and character in women with postpartum depression. Arch Womens Ment Health. 2007; 10(1):3-7. https://doi.org/10.1007/s00737-006-0159-3

25. 24. Sunay Z, Karataş Okyay E, Gökbulut N, Uçar T. The relationship of postpartum depression with personality traits. Journal of Inonu University Health Services Vocational School. 2021; 9(1):219-29. https://doi.org/10.33715/inonusaglik.813014

26. Brown A. Maternal trait personality and breastfeeding duration: the importance of confidence and social support. J Adv Nurs. 2014; 70(3):587-98. https://doi.org/10.1111/jan.12219

27. Marín-Morales D, Carmona Monge FJ, Peñacoba-Puente C. Personality, depressive symptoms during pregnancy and their influenceon postnatal depression in Spanish pregnant Spanish women. Anales De Psicología 2014; 3:908-15. https://doi.org/10.6018/ analesps.30.3.153101

28. Roman M, Bostan CM, Diaconu-Gherasim L, Constantin T. Personality Traits and Postnatal Depression: The mediated role of postnatal anxiety and moderated role of type of birth. Front Psychol. 2019; 10:1625. https://doi.org/10.3389/fpsyg.2019.01625

29. Güven Santur S, Özşahin Z. Pain in the phases of women's life and midwifery approach. In: Chernopolskı PM, Shapekova LN, Ak B editors.Research Advancements In Health Sciences. St. Kliment Ohridski University Press; 2021. p.337-55.

30. Garramone F, Baiano C, Russo A, D'Iorio A, Tedeschi G, Trojano L, Santangelo G. Personality profile and depression in migraine: a meta-analysis. Neurol Sci. 2020;41(3):543-554. https://doi.org/10.1007/s10072-019-04174-x

31. Tüzün EH, Karaduman AA, Eker L. Personality traits in migraine and tension-type headache. Physiotherapy Rehabilitation. 2003; 14(2):53-8.

32. Lewis EG, Cardwell JM. The big five personality traits, perfectionism and their association with mental health among UK students on professional degree programmes. BMC Psychol. 2020; 8(1):54. https://doi.org/10.1186/s40359-020-00423-3

33. Kaya N, Taştan N. A Review on Self-confidence. KUJSS. 2020; 10.2: 297-312. https://doi.org/10.35378/gujs.559548

34. Rahimparvar SFV, Hamzehkhani M, Geranmayeh M, Rahimi R. Effect of educational software on self-efficacy of pregnant women to cope with labor: a randomized controlled trial. Arch Gynecol Obstet. 2012; 286(1):63-70. https://doi.org/10.1007/s00404-012-2243-4

35. Islam MJ, Broidy L, Mazerolle P, Baird K, Mazumder N, Zobair K M. Do maternal depression and self-esteem moderate and mediate the association between intimate partner violence after childbirth and postpartum suicidal ideation? Arch Suicide Res. 2020; 24(4):609-32. https://doi.org/10.1080/13811118.2019.1655507

36. Ural O, Polat O, Bilgin H, Unsal FO, Kucukoglu E, Celik B, Kutluata A. Evaluation of the effect of marmara family skills training program on the self-efficiency levels and support skills of parents. HAYEF: Journal of Education 2021; 18(2):116-49. https://doi. org/10.5152/hayef.2021.20047 